\title{
Effect of light on juvenile walleye pollock shoaling and their interaction with predators
}

\author{
Clifford H. Ryer*, Bori L. Olla \\ Fisheries Behavioral Ecology Group, Alaska Fisheries Science Center, National Marine Fisheries Service, NOAA, \\ Hatfield Marine Science Center, Newport, Oregon 97365, USA
}

\begin{abstract}
Research was undertaken to examine the influence of light intensity on the shoaling behavior, activity and anti-predator behavior of juvenile walleye pollock Theragra chalcogramma. Under a $12 \mathrm{~h} \mathrm{light/12} \mathrm{h}$ dark photoperiod, juveniles displayed a diurnal shoaling and activity pattern, characterized by fish swimming in cohesive groups during the day, with a cessation of shoaling and decreased swimming speeds at night. Prior studies of schooling fishes have demonstrated distinct light thresholds below which schooling abruptly ceases. To see if this threshold effect occurs in a predominantly shoaling species, like juvenile walleye pollock, another experiment was undertaken in which illumination was lowered by orders of magnitude, giving fish $20 \mathrm{~min}$ to adapt to each light intensity. Juvenile walleye pollock were not characterized by a distinct light threshold for shoaling; groups gradually dispersed as light levels decreased and gradually recoalesced as light levels increased. At light levels below $2.8 \times 10^{-6} \mathrm{HE} \mathrm{s}^{-1} \mathrm{~m}^{-2}$, juvenile walleye pollock were so dispersed as to no longer constitute a shoal. Exposure to simulated predation risk had differing effects upon fish behavior under light and dark conditions. Brief exposure to a model predator in the dark caused fish to swiul fasier, for 5 or 6 min, than fish which had been similarly startled in the light. Chronic exposure to a living predator produced similar results; fish tended to swim slower when a predator was present in the light, but faster when a predator was present in the dark. In the light, shoaling and/or schooling provide protection against predators. But in the dark, with fish unable to see one another, increased prey activity resulting from predator disturbance may lead to accelerated dispersal of prey shoals. Thus, perceived predation risk may have different effects upon the spatial distribution of juvenile walleye pollock under light and dark conditions. This has implications for survival, as fish which have become widely scattered during the darkness may take longer to reform shoals at dawn, resulting in greater predation risk.
\end{abstract}

KEY WORDS: Schooling - Spatial distribution - Twilight hypothesis Predator-prey S Swimming speed . Illumination

\section{INTRODUCTION}

The means by which fish form and maintain shoals and schools has long been of interest to fisheries scientists and behavioral ecologists. Since the early investigations of schooling, it has been evident that the amount of light reaching the fish's eye largely determines whether or not it is able to school (Breder 1951, Atz 1953, Shaw 1961, Hunter 1968). Although other senses, such as the lateral line system, may play an important role in the spatial and angular orientation of in-

\footnotetext{
•E-mail: cliff.ryer@hmsc.orst.edu
}

dividuals within a school (Partridge \& Pitcher 1980), it is unlikely that in the wild many species are capable of schooling in the absence of sufficient light. This impression is supported by observational (Emery 1973, Helfman 1979) and bioacoustical studies which generally show that shoals and schools disperse at night (Appenzeller \& Leggett 1992, Brodeur \& Wilson 1996). Since ambient light in marine and aquatic habitats may vary greatly according to depth, turbidity, season, lunar stage and cloud cover (McFarland 1986), the meaning of 'night', relative to light levels, is rather ambiguous. Numerous studies have been directed towards determining the relationship between light intensity and some measure of the ability or inclination of fish to form 
cohesive groups. In some species there is a gradual decrease in schooling or shoaling as light levels decrease (John 1964), while for others, there is a threshold light level at which this behavior abruptly ceases. This threshold varies from $3.7 \times 10^{-2} \mu \mathrm{E} \mathrm{s}^{-1} \mathrm{~m}^{-2}$ for the Hawaiian silverside Pranesus insularum (Major 1977) to $1.8 \times 10^{-7} \mu \mathrm{E} \mathrm{s} \mathrm{s}^{-1} \mathrm{~m}^{-2}$ for the Atlantic mackerel Scomber scombrus (Glass et al. 1986), with most other species examined falling somewhere between these extremes (Higgs \& Fuiman 1996). Putting this in an ecological context, Glass et al. (1986) concluded that Atlantic mackerel should be able to school to depths of $20 \mathrm{~m}$ on clear starlit nights and perhaps to 80 or $100 \mathrm{~m}$ on clear moonlit nights, whereas cloud cover could make schooling at night impossible, even at the surface.

One of the well-established functions of gregarious behavior, e.g. shoaling, schooling, flocking and herding, is to facilitate the individual's ability to detect and mitigate predatory threat (Lazarus 1979). Individuals in groups are likely to detect predators at greater distances (Magurran et al. 1985) and are often less vulnerable due to coordinated escape responses (Pitcher \& Parrish 1993) which result in predator confusion (Neill \& Cullen 1974, Landeau \& Terborgh 1986) as well as dilution/attack abatement effects (Bertram 1978, Turner \& Pitcher 1986). Attacks by predators are frequently concentrated during twilight periods (Major 1977, Parrish 1992), when prey are silhouetted against the downwelling light from the surface and predators approaching from below are difficult for prey to detect against the darkness of the depths (Munz \& McFarland 1973). Yet, little is known about how predators and prey interact in darkness and how this will influence the spatial distribution of prey. With their dependence upon vision, it is clearly not feasible for most shoaling and schooling species to maintain, much less form, more cohesive groups in the dark. However, fish may have evolved other behaviors that minimize their nocturnal vulnerability and perhaps facilitate the reformation of groups at dawn. Some fish species decrease their activity during the night (Emery 1973, Helfman 1993) to conserve energy and possibly to reduce conspicuousness to predators. For shoaling and schooling fish, this may also minimize group dispersal and decrease the time required for individuals to locate conspecifics and reform shoals or schools at dawn. Several studies have shown that, with the onset of morning twilight, fish begin forming groups before they commence other activities such as feeding (Helfman 1979, Pitcher \& Turner 1986). Since twilight is a period of intense predation, any influence that predators have upon the dispersal of prey during the darkness, thereby influencing the speed of group reformation at dawn, should influence individual vulnerability to predation at dawn.
In this paper we examine the influence of light on the shoaling and anti-predator behavior of juvenile walleye pollock Theragra chalcogramma. The walleye pollock is a pelagic species of the northern Pacific Ocean which supports a large commercial fishery and, in its juvenile phase, is preyed upon by numerous species of groundfish, birds and marine mammals (Livingston 1993). For juveniles, gregarious behavior typically consists of shoaling (Pitcher 1980), with fish forming loosely structured groups (Ryer \& Olla 1995). Juveniles will form more highly structured schools (Pitcher 1980), but only when they are rapidly moving from one location to another. In the Bering Sea, juvenile walleye pollock have been reported to exhibit a diel pattern of vertical migration, moving upwards into surface waters during dusk, followed by a return to depth around dawn (Bailey 1989, Tang et al. 1996). In the western Gulf of Alaska, Brodeur \& Wilson (1996) observed a similar diel migration, but also reported that juveniles formed highly cohesive aggregations near the bottom during the day and dispersed in the surface waters during the night. Without knowledge of the in situ light levels and light thresholds for shoaling behavior, it is impossible to know whether such dispersive behavior results from fish actively leaving social groups to individually seek out prey (Ryer \& Olla 1995), or from the inability of fish to maintain shoals at the ambient light levels involved. A prior laboratory study demonstrated that juvenile walleye pollock shoals become less cohesive at night (Sogard \& Olla 1996). But, this study utilized a night-time light level of $0.1 \mu \mathrm{E} \mathrm{s}^{-1} \mathrm{~m}^{-2}$, which is more typical of twilight than night-time, leaving open the question of how lower light levels influence shoaling. Beyond its interest from a purely ecological perspective, knowledge of distribution patterns in juvenile shoaling and schooling fishes, and the underlying mechanisms which produce them, may aid in designing the sampling protocols needed to predict future abundance of these species (Neilson \& Perry 1990).

To address the relationship between light and shoaling in juvenile walleye pollock, we examined the shoaling intensity and swimming speeds of juvenile walleye pollock over 2 consecutive days under a $12 \mathrm{~h}$ light/12 h dark photoperiod, to elucidate diel patterns of behavior in the laboratory. Next, we conducted an experiment to see if there is a distinct threshold light level at which shoaling ceases, decreasing illumination from $3.9 \mu \mathrm{E} \mathrm{s}^{-1} \mathrm{~m}^{-2}$ to darkness in incremental order of magnitude steps, and then incrementally increasing light back to the $3.9 \mu \mathrm{E} \mathrm{s}^{-1} \mathrm{~m}^{-2}$ level. At each level we monitored shoal behavior and activity.

If the dispersal of juvenile walleye pollock in darkness results from an inability to shoal, the rate of dispersal may be influenced by any factor which affects fish activity. When there is adequate light for shoaling, 
the presence of predators has been shown to decrease juvenile walleye pollock swimming speeds (Ryer \& Olla 1997). However, in preliminary experiments we noted that juvenile walleye pollock startled by human activity in the darkness tended to become agitated and more active than juveniles startled in the light. We hypothesized that juvenile walleye pollock would also become more active in response to predators in the darkness. To test this, we conducted 2 experiments; first, juvenile walleye pollock were exposed to a simulated attack by a model predator under both light and dark conditions, and second, juveniles were exposed to the more persistent threat of a live predator in both the light and the dark. For both experiments we monitored shoal cohesiveness and swimming speeds of the fish.

\section{MATERIALS AND METHODS}

Fish collection and maintenance. During June of 1995 and 1996, juvenile walleye pollock were collected at night from Puget Sound, Port Townsend, WA, USA, by dipnetting them as they aggregated around a light suspended above the water's surface. At the time of collection, juveniles ranged from 20 to $50 \mathrm{~mm}$ total length. Fish were transported back to our laboratory in Newport, OR, USA, and maintained in $3000 \mathrm{l}$ circular tanks provided with a continuous flow of seawater; saininity range 28 to $33 \%$, temperature range 9 to $13^{\circ} \mathrm{C}$. Juvenile sablefish Anaplopoma fimbria, used as predators, were captured during April 1996 using a neuston net during the night, approximately $32 \mathrm{~km}$ off Newport. Both species were fed pelletized food daily, and while the exact ration was not measured, it was sufficient to promote growth.

Infrared observation arena. The arena consisted of a fiberglass circular tank $(190 \times 76 \mathrm{~cm}, \mathrm{~W} \times \mathrm{H})$ with a $19 \mathrm{~mm}$ thick plexiglass bottom (Fig. 1). It was positioned $64 \mathrm{~cm}$ of the floor, supported around its periphery by cinder blocks and across its center by a narrow support wall that bisected the tank bottom. The area under the arena was lined with aluminum foil to provide a reflective surface and then surrounded with black plastic to prevent light leakage. The tank was illuminated from below with four $60 \mathrm{~W}$ LED infrared (IR) illuminators. The wavelength of emitted light peaked at $880 \mathrm{~nm}$, with no emissions below $760 \mathrm{~nm}$. Previous studies indicate that fish are insensitive to light in this range (John 1964, Pitcher \& Turner 1986, Higgs \& Fuiman 1996). The IR illuminators were positioned under the arena around its periphery and aimed downward onto the aluminum foil, which scattered and reflected the IR light upwards through the arena bottom. The bottom of the arena was also lined with a plastic light-diffusing material, commonly used

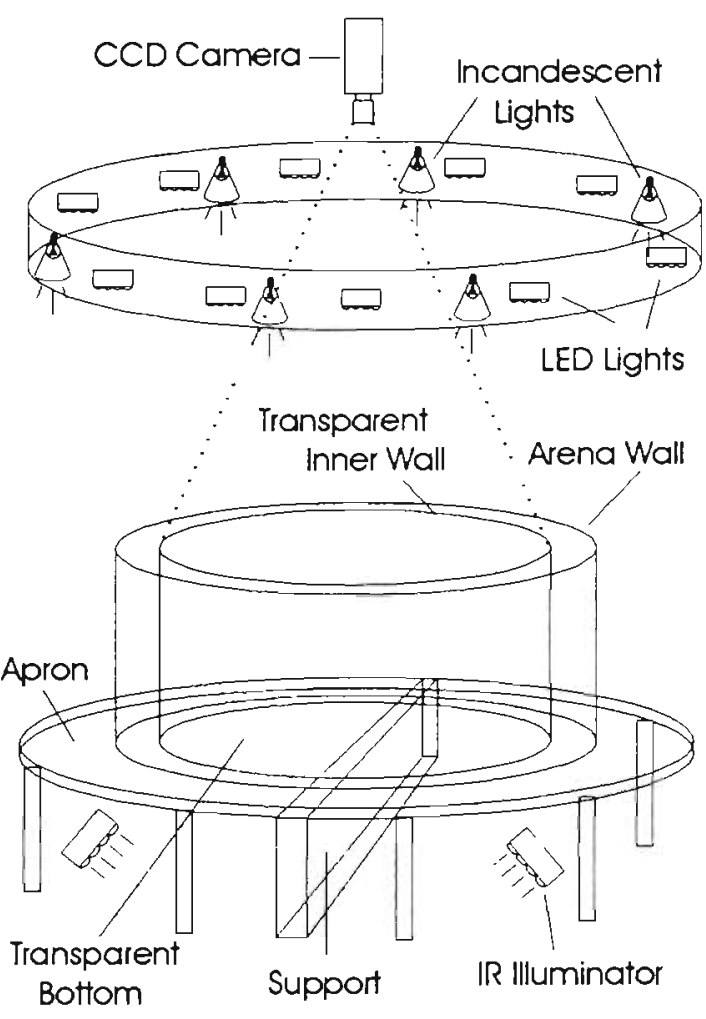

Fig. 1. Experimental infrared (IR) arena. Surrounded by a blind in a dark room, fish were viewed as silhouettes against a uniform bright background from above with an IR sensitive camera. In lighitiny was provided by tour $60 \mathrm{~W}$ LED illuminators located below the transparent bottom of the arena. The IR illuminators were aimed downwards, so their light was bounced off reflective foil on the floor beneath the arena and upward through the transparent arena bottom. An inner transparent wall (cylinder) was positioned inside the arena and prevented fish from swimming along the arena walls, where they would not be silhouetted from below. Visible light was provided by a combination of incandescent and green LED illuminators located above the arena

in overhead fluorescent fixtures, thereby producing a uniformly illuminated background against which fish could be viewed from above. A video camera, with spectral sensitivity well into the IR range, was positioned $2.4 \mathrm{~m}$ above the arena and cabled to a video recorder and monitor in another room. A circular clear plexiglass inner wall $(150 \times 76 \mathrm{~cm}, \mathrm{~W} \times \mathrm{H})$ was centrally positioned in the arena to keep fish away from the outer arena wall where they would not be visible to the camera. This inner wall had numerous $5 \mathrm{~mm}$ holes in it, which allowed water to pass from this inner area to the outer area of the arena. Four seawater inflow pipes extending vertically to within $3 \mathrm{~cm}$ of the arena bottom were positioned at equal distances around the periphery of the inner wall, supplying seawater to the central area of the arena, while a single drain hole in the outer arena wall at a height of $30 \mathrm{~cm}$ allowed outflow of water. 
Six $60 \mathrm{~W}$ incandescent lights with aluminum reflector cones were positioned $2.4 \mathrm{~m}$ above the floor, equally spaced in a $3.6 \mathrm{~m}$ diameter circle centered on the arena. Lights were controlled by a timer set to a photoperiod of $12 \mathrm{~h}$ light/12 $\mathrm{h}$ dark. Rather than instantly turning the lights on or off, the timer initiated a gradual dimming or raising of the lights which lasted roughly 75 min, simulating morning and evening twilight. At full illumination, these lights produced $2.1 \mu \mathrm{E}$ $\mathrm{s}^{-1} \mathrm{~m}^{-2}$, measured at the water's surface with a research radiometer equipped with a detector sensitive to $1 \times 10^{-8} \mu \mathrm{E} \mathrm{s}^{-1} \mathrm{~m}^{-2}$. This lighting arrangement was utilized for the shoaling and activity periodicity experiment conducted during the fall of 1995 . For subsequent experiments, conducted during the summer of 1996, a set of 10 equally spaced LED illuminators was added to the ring of lighting, allowing more precise control of low illuminations. Each illuminator consisted of 10 individual green LEDs. These illuminators emitted at $555 \mathrm{~nm}$ and, when operated independently of the incandescent lighting, allowed incremental manipulation of light from $4.2 \times 10^{-3}$ to $4.0 \times 10^{-7} \mathrm{\mu E} \mathrm{s}^{-1} \mathrm{~m}^{-2}$, measured at the water's surface. Operated in tandem, the incandescent and green LED lights allowed manipulation of illumination in the range of 3.9 to $4.0 \times 10^{-7}$ $\mu \mathrm{E} \mathrm{s} \mathrm{s}^{-1} \mathrm{~m}^{-2}$.

Periodicity of shoaling and activity. Four juvenile walleye pollock were haphazardly selected from holding tanks and introduced to the arena at approximately 14:00 h. Incandescent lights provided $2.1 \mathrm{kE} \mathrm{s}^{-1} \mathrm{~m}^{-2}$ during the day. The light level during the night was below detection limits $\left(<1 \times 10^{-8} \mu \mathrm{E} \mathrm{s}^{-1} \mathrm{~m}^{-2}\right)$. Lights began to dim at 19:00 h and were off by $20: 20 \mathrm{~h}$, and began to rise again at $07: 00 \mathrm{~h}$, reaching day levels by 08:20 h. Fish were fed pelletized food at 11:00 h each day. Videotaping occurred over 2 consecutive days at $17: 00-17: 15, \quad 21: 00-21: 15, \quad 01: 00-01: 15, \quad 05: 00-05: 15$, 09:00-09:15 and 13:00-13:15 h, beginning on the same afternoon fish were introduced to the arena. After the last videotape focal period, the group of fish was removed from the arena, anesthetized using MS222, weighed and measured, and replaced with a fresh group of 4 fish. Seven replicate groups were examined in this manner.

As an index of shoal cohesion, we measured nearestneighbor distances (Clark \& Evans 1954) and calculated the average nearest-neighbor distance for each group from videotapes at 3 min intervals during the 15 min focal periods. We then calculated the mean of these 5 average nearest-neighbor distances. As an indicator of activity, we measured the swimming speed of randomly chosen individuals over a 1 min time span, using a video digitization system. These swimming speed measurements were made at 3 min intervals and then averaged over the $15 \mathrm{~min}$ focal period. In this and all subsequent experiments, swimming speeds were converted to body lengths $s^{-1}$, dividing swimming speed by the average fish length for a given group. All data were homoscedastic $\left(F_{\max }\right.$-test; Sokal \& Rohlf 1969) and appeared normally distributed (rankit plots; Sokal \& Rohlf 1969]. Data were analyzed using repeated-measures ANOVA (Hicks 1982), examining the effect of hour $(17: 00,21: 00,01: 00,05: 00,09: 00$, $13: 00 \mathrm{~h}$ ) and day $(1,2)$. Where statistical effects were considered significant ( $\mathrm{p}<0.05$ ), a posteriori multiple comparisons were conducted utilizing Ryan's Q-test (Day \& Quinn 1989).

Light-shoaling threshold determination. Six fish were haphazardly selected from stock tanks and introduced to the arena at approximately 15:00 h. The following morning, at approximately 09:00 h, we began to incrementally lower the illumination in order of magnitude steps, pausing at each level for 20 min and videotaping the group. The light was manipulated using both incandescent and green LED lights in tandem. The starting level was $3.9 \mu E \mathrm{~s}^{-1} \mathrm{~m}^{-2}$, achieved with both incandescent and green LED lights on full. For each of the next 2 steps, $3.9 \times 10^{-1}$ and $3.9 \times 10^{-2} \mu \mathrm{E}$ $\mathrm{s}^{-1} \mathrm{~m}^{-2}$, the incandescent lights were dimmed while the green LEDs remained on full. This resulted in some degree of spectral shift as the light dimmed, which we did not measure. For subsequent light levels, $4.2 \times 10^{-3}$ $4.3 \times 10^{-4}, 4.5 \times 10^{-5}, 4.1 \times 10^{-6}$ and $<1 \times 10^{-8} \mu \mathrm{E} \mathrm{s}^{-1} \mathrm{~m}^{-2}$ (darkness), the green LEDs alone were utilized, and the spectral character of the light remained constant. After 20 min in the dark, the process was reversed and the lights were incrementally brought back up to the starting level. Including both the decreasing and increasing light phases, this resulted in 15 light level periods. Groups were removed from the arena $2 \mathrm{~d}$ later, after use in a model predator experiment, anesthetized, weighed and measured. Seven replicate groups were experimented with in this manner. From videotapes we quantified nearest-neighbor distances from the last $3 \mathrm{~min}$ of each light level period, which allowed 17 min for fish to have adjusted to their new light regime. Nearest-neighbor distances were measured and the average nearest-neighbor distance calculated at 30 s intervals, yielding 5 average values, which were subsequently averaged for that period. The swimming speed of each fish was measured during the 17 th min of each period, and an average speed calculated for each period. Both nearest-neighbor distance data and swimming speeds were homoscedastic, appeared normally distributed and were analyzed using repeated measures ANOVA and Ryan's $Q$-test multiple comparisons.

Simulated predator attack experiment. Fish were kept in the arena after the light-shoaling threshold test, and at approximately 14:00 $\mathrm{h}$ the next day, with 
illumination set at $2.1 \mu \mathrm{E} \mathrm{s}^{-1} \mathrm{~m}^{-2}$, we began videotaping the arena. After $30 \mathrm{~min}$ a $25 \mathrm{~cm}$ generic model fish 'predator', on a $1 \mathrm{~m}$ string attached to a stick, was plunged into the center of the arena and surged back and forth for $5 \mathrm{~s}$, then rapidly removed. Videotaping was continued for another $90 \mathrm{~min}$. The next day, the procedure was repeated in the dark $\left(<1 \times 10^{-8} \mu \mathrm{E} \mathrm{s}^{-1}\right.$ $\mathrm{m}^{-2}$ ), with the lights having been gradually dimmed and then completely off for 90 min prior to the beginning of videotaping. Nearest-neighbor distances were measured and average nearest-neighbor distances calculated at $3 \mathrm{~min}$ intervals during the pre-predator fright period. After model predator application, the ripples and waves on the waters surface hindered video viewing of fish for up to $90 \mathrm{~s}$. Two min after the model predation application, measurement of nearest-neighbor distances were initiated at $1 \mathrm{~min}$ intervals. This continued for $10 \mathrm{~min}$, after which nearest-neighbor distances were measured at 15 min intervals. Swimming speeds were measured with the same frequency, with a single fish randomly chosen for each $1 \mathrm{~min}$ focal period. Both nearest-neighbor and swimming speed data required rank transformation to achieve homogeneity of variance and subsequently also appeared normally distributed. Data were analyzed using repeated measures ANOVA and Ryan's Q-test multiple comparisons.

Live predator experiment. For predator trials, 10 hâphazardily selecied juvenile waileye pollock were removed from stock tanks and placed in the arena at approximately 09:00 h. The predator, a single sablefish, was haphazardly selected from a stock tank containing between 8 and 16 juvenile sablefish and placed in the arena $1 \mathrm{~h}$ later. These sablefish ranged in total length from 133 to $190 \mathrm{~mm}$ and have been demonstrated in laboratory studies to be piscivorous and will readily attack and attempt to consume juvenile walleye pollock (Ryer \& Olla 1998). Both predator and remaining prey were removed, measured and weighed the following day at $08: 00 h_{i}$ juvenile walleye pollock ranged in total length from 63 to $94 \mathrm{~mm}$, with a mean of $78 \mathrm{~mm}$. Control trials were conducted according to the same protocol, except no sablefish predators were introduced to the arena. Predator and control trials were conducted in 11 matched pairs, with the control trial conducted the day after each predator trial. The number of juvenile walleye pollock (prey) that had been consumed by $17: 00 \mathrm{~h}$ in predator trials determined the number of prey used in the control on the next day. In both predator and control trials, fish were videotaped for $5 \mathrm{~h}$, starting at 16:30 h. From these tapes we quantified juvenile walleye pollock behavior during 30 min periods beginning at $17: 30 \mathrm{~h}$ (light $=2.1 \mu \mathrm{E} \mathrm{s}^{-1} \mathrm{~m}^{-2}, 90 \mathrm{~min}$ before the beginning of evening twilight) and $21: 00 \mathrm{~h}(45 \mathrm{~min}$ after darkness, light $<1 \times 10^{-8} \mu \mathrm{E} \mathrm{s}^{-1} \mathrm{~m}^{-2}$ ). We measured nearest-neighbor distances, calculating average nearest-neighbor distance, and measured the swimming speed of randomly chosen fish at 3 min intervals. Graphs of these data suggested no change in either nearest-neighbor data or swimming speed through the observation period, so data were averaged by group. Data were rank transformed to achieve homogeneity of variance and normality and analyzed using repeated measure ANOVA. For predator trials, we recorded the number of attacks by the predator over $30 \mathrm{~min}$, as well as the number of times the predator appeared to orient towards and approach prey in the darkness. We also counted the number of prey-on-prey chases, comparing their frequency between predator and control treatments with a paired $t$-test. Since prior work led us to expect chasing to be less frequent in the predator trials (Ryer \& Olla 1998), this test was 1-tailed (Sokal \& Rohlf 1969).

\section{RESULTS}

\section{Periodicity of shoaling and activity}

Juvenile walleye pollock engaged in cohesive shoaling during the day, but dispersed during the night. This pattern was reflected in nearest-neighbor distances (Fig 2a), and although the difference between day and night-time hours varied slightly between the 2
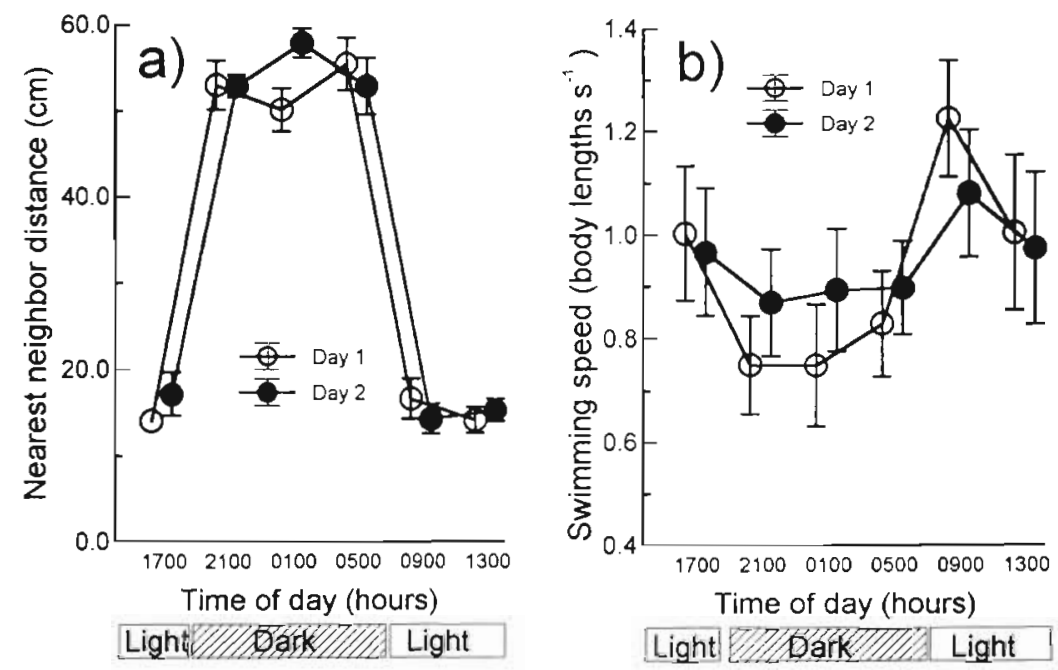

Fig. 2. Periodicity experiment. (a) Mean nearest-neighbor distances $( \pm \mathrm{SE}$ ) (b) Mean swimming speeds ( $\pm \mathrm{SE}$ ) over 2 consecutive $24 \mathrm{~h}$ periods 

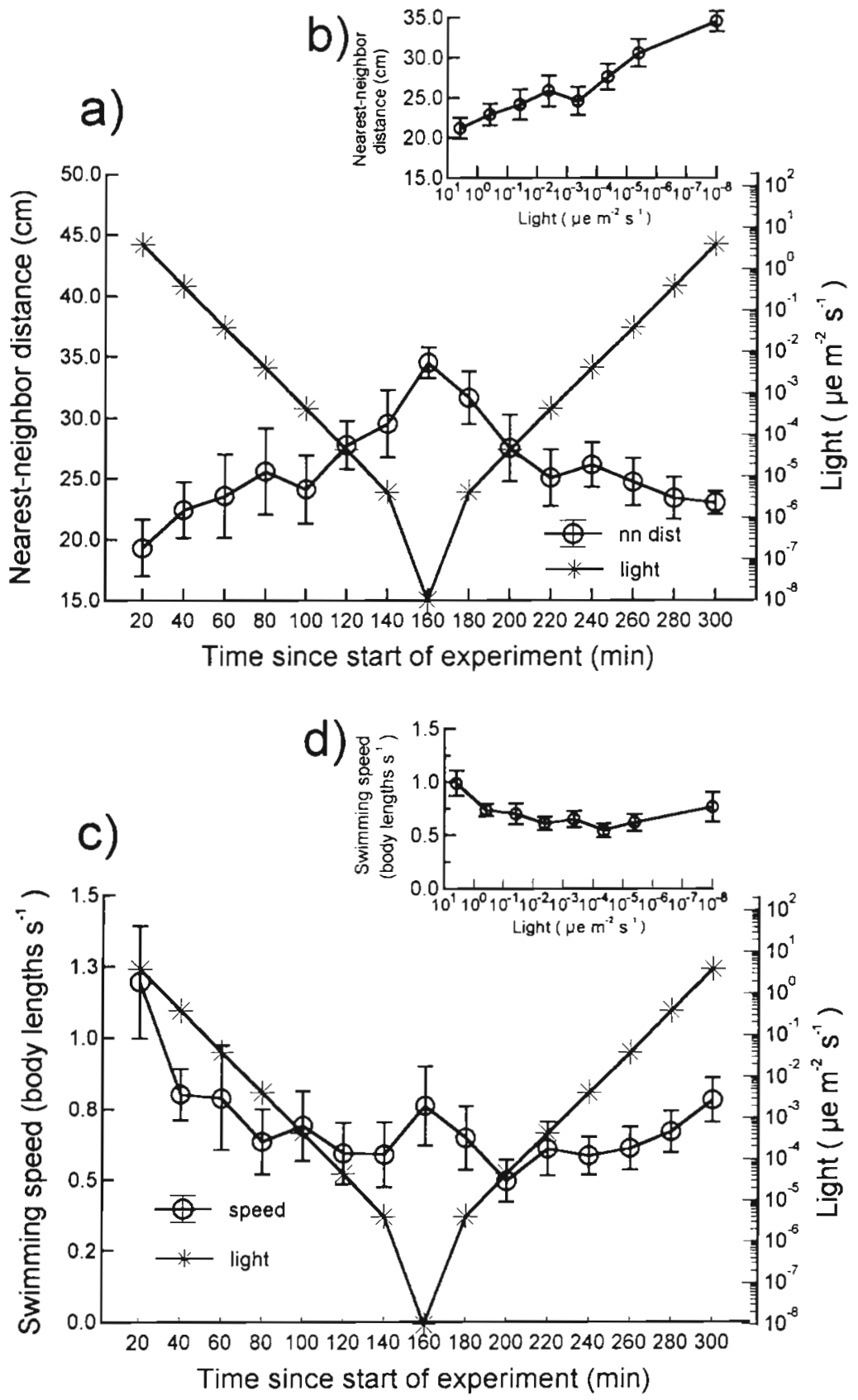

Fig. 3. Light threshold experiment. (a) Mean nearest-neighbor distances $( \pm \mathrm{SE})$ as light levels were incrementally decreased and then increased again. Fish were given 20 min acclimation at each light level. (b) Mean nearestneighbor distances ( $\pm \mathrm{SE}$ ) plotted as a function of illumination. (c) Mean swimming speeds $( \pm S E$ ) with incremental light change. (d) Mean swimming speeds as a function of illumination

days of the experiment (time $\times$ day interaction: $F=$ 2.55, $\mathrm{df}=5, \mathrm{p}=0.049$ ), nearest-neighbor distances were consistently greater in the dark than in the light during both days (multiple comparisons). Changes in activity also reflected a diel periodicity, but one which was less pronounced than that observed for schooling (Fig. 2b). Low swimming speeds at night were fol- lowed by a significant increase during the morning, which was then followed by a decrease during the day to intermediate levels that did not differ from either the morning high or the night-time lows (multiple comparisons; ANOVA: $F=$ 5.79, $\mathrm{df}=5, \mathrm{p}=0.001$ ). As was the case for nearest-neighbor distances, the pattern for swimming speed was similar during both days of the experiment $(F=$ 02.06, $\mathrm{df}=5, \mathrm{p}=0.099)$, suggesting that walleye pollock behavior did not change over the $2 \mathrm{~d}$ experiment as a result of acclimation to the arena.

\section{Influence of illumination on shoaling and swimming speed}

Juvenile walleye pollock did not exhibit a distinct illumination threshold for shoaling or activity. As illumination was lowered by orders of magnitude from full light to darkness, with fish given 20 min to adapt to each illumination level, juvenile walleye pollock exhibited a gradual decrease in shoal cohesiveness, as demonstrated by increasing nearestneighbor distances (Fig. 3a). Subsequent order of magnitude increases in illumination produced corresponding increases in shoal cohesion. Nearestneighbor distances changed significantly through the experiment (ANOVA: $F=$ $2.62, \mathrm{df}=14, \mathrm{p}=0.003$ ), but in a graded manner, with multiple comparisons revealing 3 largely overlapping homogeneous subgroups of means. More importantly, in 12 out of 14 changes in illumination, the observed direction of change in mean nearest-neighbor distance was consistent with that predicted by assuming a negative relationship between nearest-neighbor distance and light level. This represents a significant departure from the null model of no association between light and nearestneighbor distance (Sign test, $p=0.006$ ), further indicating that shoaling decreases with decreasing illumination. The 2 exceptions to this pattern occurred at $4.3 \times 10^{-4} \mu \mathrm{E} \mathrm{s}^{-1} \mathrm{~m}^{-2}$, on both the ascending and descending limbs of the light response curve (Fig. 3a). When nearest-neighbor distance is plotted as a function of the natural log of light level, the mean nearest-neighbor distance at $4.3 \times 10^{-4} \mu \mathrm{E} \mathrm{s}^{-1} \mathrm{~m}^{-2}$ is 
suggestive of a discontinuity in what otherwise would appear to be a linear relationship (Fig. 3b). Comparing nearest-neighbor distances between Fig. $3 a$ and Fig. 2a, it would appear that group cohesion was greater in the dark during the day than it was in the dark during the night. This is most probably an artifact of the differing numbers of fish used in these 2 experiments. The arena size was the same for both, but in the periodicity study, groups of 4 fish were utilized, compared to groups of 6 in the threshold study.

Swimming speed was less clearly related to illumination than shoaling (Fig. 3c). The only significant effect was that swimming speed at the beginning of the experiment, i.e. $20 \mathrm{~min}$, was higher than during the remainder of the experiment (multiple comparisons, ANOVA: $F=7.64, \mathrm{df}=14, \mathrm{p}<0.001$ ). Further, although 9 out of 14 illumination changes were consistent with $a$ positive relationship between swimming speed and light level, this result did not differ significantly from the null model of no association (Sign test, $p=0.212$ ). Similarly, plotting swimming speed by natural-logtransformed light level suggests no obvious relationship (Fig. 3d).

\section{Effect of simulated predator attack upon shoaling and swimming speed}

As seen in the 2 prior experiments, juvenile walleye pollock shoaled in the light, but swam about independently in the dark (Fig. 4a). Throughout the pre-exposure period, nearest-neighbor distances were lower in the light than in the darkness (multiple comparisons; time $\times$ light level interaction: $F=1.97, \mathrm{df}=24, \mathrm{p}=$ $0.007)$. The model predator had a transitory effect upon this light/dark difference in shoaling. During the $5 \mathrm{~s}$ model predator presentation, fish scattered and darted about, after which some individuals remained motionless on the arena bottom for up to $90 \mathrm{~s}$, often aggregating next to or behind water inflow pipes. As a result, 2 min after the model presentation, nearest-neighbor distances were equal under both light and dark conditions (multiple comparisons). However, 4 min after the simulated attack, fish in the light were again shoaling, with their nearest-neighbor distances lower than those of fish in the darkness (multiple comparisons). This difference in shoaling behavior persisted through the remainder of the experiment (multiple comparisons). Other than the brief period immediately after the simulated attack, there was no difference in nearestneighbor distances between before and after periods in the darkness (multiple comparison). In the light, there was a trend towards more cohesive shoaling after the simulated attack, but this was not statistically significant (multiple comparisons).
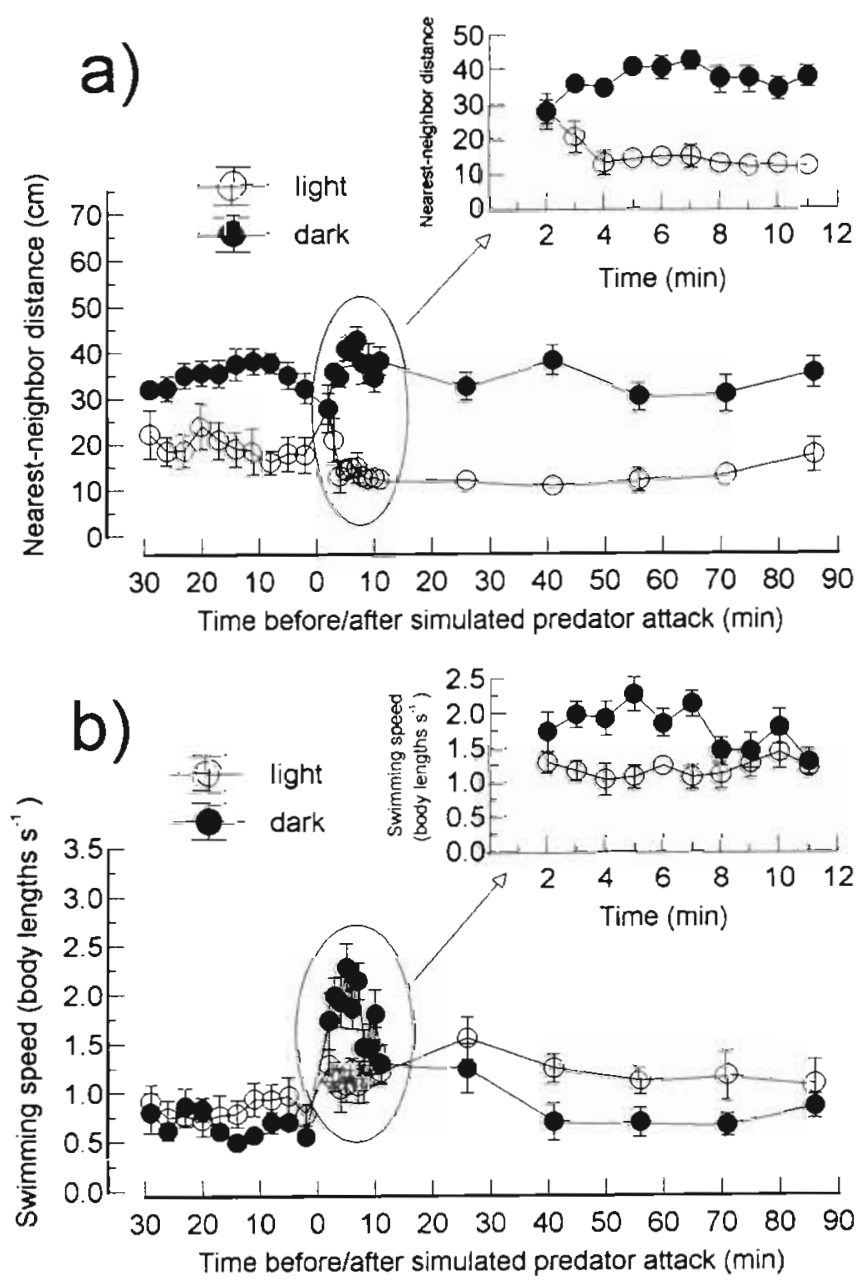

Fig. 4. Model predator experiment. (a) Mean nearest-neighbor distances ( \pm SE) before and after a 5 s exposure to a model fish predator both in the light and in the dark. (b) Mean swimming speeds $( \pm \mathrm{SE}$ ). Insets in both (a) and (b) show, in an expanded time scale, the period immediately following simulated attack by the model predator

Model presentation had a pronounced effect upon activity, particularly for fish in the dark (Fig. $4 \mathrm{~b}$; time $\times$ light level interaction: $F=5.80, \mathrm{df}=24, \mathrm{p}<0.001$ ). Prior to the presentation, swimming speed tended to be lower in the dark than in the light (significantly so 14 and 11 min beforehand, multiple comparison). After the presentation, swimming speed increased under both light and dark conditions (multiple comparisons). However, this increase was greater in the dark, so that by 3 min after the presentation, fish in the dark were swimming faster than those in the light (significant differences at minutes 3,4 , 5 and 7 , multiple comparisons). This sharp increase in the swimming speed in the dark was transitory and 8 min after the attack fish had slowed to speeds comparable to those exhibited by fish in the light (no significant differences for minutes 8 to 26 , multiple comparisons). Forty-one min after the model predator presentation, fish 
in the dark again tended to swim slower than fish in the light (significant differences at minutes 41,56 and 71, multiple comparisons).

\section{Effect of a live predator upon shoaling and swimming speed}

An average of 1.55 juvenile walleye pollock ( $S D=$ 1.42) were consumed in the predator trials, although none were consumed during the two 30 min observation periods, and none were consumed in the darkness. Attacks by the predator were frequent in the light $\left(36.4 \mathrm{~h}^{-1}, \mathrm{SD}=30.2\right)$, but no attacks were observed in the darkness. Although the predator appeared able to detect and approach prey from a range of several $\mathrm{cm}$ in the darkness, these approaches were infrequent $\left(3.5 \mathrm{~h}^{-1}, \mathrm{SD}=3.4\right)$ and juvenile walleye pollock darted away as soon as the predator drew near, with no attempted pursuit by the predator. Other than these infrequent close encounters, juvenile walleye pollock did not appear to actively avoid predators in the dark. In contrast, in the light, walleye pollock shoaling was frequently disrupted, as individuals and small groups of fish moved in different directions to avoid the approaching predator. In addition, individual fish would often separate from the shoal, approach, and sometimes follow the predator. This inspection behavior was most prevalent when the fish had not recently been chased.

Beyond an obvious effect of light on shoaling $(F=$ $73.21, \mathrm{df}=1, \mathrm{p}<0.001$ ), there was no statistically significant effect of predator presence on shoaling (Fig. 5a) $(F=0.22, \mathrm{df}=1, \mathrm{p}=0.651)$, under either light or dark conditions, although in the light there was a trend for more cohesive shoaling in the presence of a predator $(F=2.52, \mathrm{df}=1, \mathrm{p}=0.144)$. Nearest-neighbor distances in the dark were generally lower than those in the prior experiments. Again, this was most probably an artifact of our having used more fish in the live predator experiment than were used in the prior experiments. Swimming speed was influenced by predator presence (Fig. 5b); in the light, swimming speed decreased when a predator was present, while in the dark it increased (light $\times$ predator interaction: $F=13.44, \mathrm{df}=1, \mathrm{p}=0.004$; multiple comparisons: Ryan's $Q$ equaled the critical value, i.e. $p=0.05$, for comparisons in both the light and the dark). This increased swimming speed in the darkness did not appear to directly result from observable interactions between predator and prey.

Aggressive interactions between juvenile walleye pollock were also influenced by predation risk. In the light, instances of walleye pollock chasing each other were less frequent when a predator was present (1-tailed $t=1.81, \mathrm{df}=10, \mathrm{p}=0.025$; no predator: $\overrightarrow{\mathrm{x}}=6.5$,
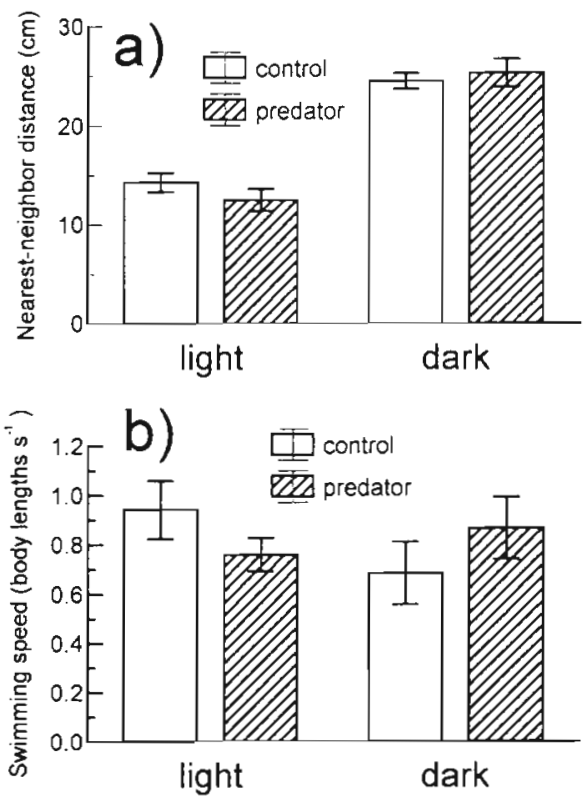

Fig. 5. Live predator experiment. (a) Mean nearest-neighbor distances $( \pm S E)$ in both the light and the dark, with and without a predator present. (b) Mean swimming speeds ( \pm SE)

$\mathrm{SE}=1.2$; predator: $\bar{X}=3.6, \mathrm{SE}=1.0$ ). Chases were not enumerated in the dark.

\section{DISCUSSION}

The diurnal pattern of shoaling we observed in fish subjected to a $12 \mathrm{~h}$ light/12 h dark photoperiod supports prior field and laboratory observations on juvenile walleye pollock (Brodeur \& Wilson 1996, Sogard \& Olla 1996) and is similar to those observed in other shoaling and schooling fish (Shaw 1961, Blaxter \& Parrish 1965, Major 1977, McFarland et al. 1979). While it is unclear to what extent endogenous rhythms influence this diurnal behavior (Neilson \& Perry 1990), it is clear that juvenile walleye pollock do not shoal in the darkness. Using lateral line systems, some fish appear to have limited ability to maintain social groupings without vision. For example, temporarily blinded saithe Pollachius virens are able to swim with a sighted school, but tend to maintain greater nearest-neighbor distances (Partridge \& Pitcher 1980). Similarly, olfaction may allow some species to stay congregated in the dark (Keenleyside 1955). We observed pairs of juvenile walleye pollock occasionally swimming together in darkness, with one fish altering its speed and direction to match the other's, falling in somewhat behind and off to one side of the leader. However, such pairing never lasted more than 4 or $5 \mathrm{~s}$ before a change in direction by one fish or the other resulted in separa- 
tion. Given the size of our experimental arena, we cannot discount the possibility that juvenile walleye pollock may utilize other senses to maintain loose congregations in the darkness, but for shoaling, vision is essential.

Ambient light levels in the ocean vary with time of day, latitude, season, cloud cover, surface turbulence, depth and turbidity, to name but a few factors (McFarland 1986). As such, using 'night-time' as a synonym for darkness is ambiguous and potentially misleading. Accordingly, numerous studies have attempted to quantify the precise light levels at which various species no longer engage in shoaling and schooling behavior, with values ranging from $3.7 \times 10^{-2} \mu \mathrm{E} \mathrm{s} \mathrm{s}^{-1} \mathrm{~m}^{-2}$ for Hawaiian silversides Pranesus insularum (Major 1977 ) to $1.8 \times 10^{-7} \mu \mathrm{E} \mathrm{s}^{-1} \mathrm{~m}^{-2}$ for Atlantic mackerel Scomber scombrus (Glass et al. 1986). Most of the species for which thresholds have been reported are fish which routinely engage in schooling, i.e. fish that move in polarized groups, in a highly synchronized manner Although juvenile walleye pollock will occasionally school, shoaling is more the norm in this species. Our results indicate that juvenile walleye pollock gradually decrease shoaling as illumination decreases, rather than displaying a distinct light threshold. Although light at a given depth in the ocean can change by as much as $50 \% \mathrm{~min}^{-1}$ during twilight periods (McFarland 1986), at the high latitudes where juvenile walleye pollock occur, twilight perıods are more prolonged, with more gradual changes in illumination at any given depth. In addition, juvenile walleye pollock migrate vertically (Bailey 1989, Merati \& Brodeur 1996. Tang et al. 1996), and since light attenuates with depth, this will also lessen the magnitude of changes in illumination they experience. These factors combined suggest that walleye pollock may experience only 2 or 3 orders of magnitude change in illumination over prolonged periods of time during their crepuscular migrations. Hence, the transition from shoaling to non-shoaling is also likely to be a gradual one.

The spectral composition of ambient light also varies temporally, with meteorological conditions and with depth (McFarland 1986), and the fish eye is differentially sensitive to various spectra (Blaxter 1964, 1969). In our threshold experiment, we utilized green light for illuminations of $4.2 \times 10^{-3} \mu \mathrm{E} \mathrm{s}^{-1} \mathrm{~m}^{-2}$ and below, since this is the most ubiquitous wavelength in coastal marine waters (McFarland 1986). Unfortunately, for higher illuminations we had to add additional incandescent lighting, which resulted in a shifting of spectral composition. Without knowing the spectral sensitivity of the juvenile walleye pollock eye, it is impossible to evaluate precisely how this shifting of wavelengths may have influenced the shape of response curve shown in Fig. 3b. However, there was no abrupt change in the light-shoaling relationship between $3.9 \times 10^{-2}$ and $4.2 \times 10^{-3} \mu \mathrm{E} \mathrm{s}^{-1} \mathrm{~m}^{-2}$, as the light went from mixed white and green to green only. Thus, while the precise shape and slope of this upper portion of the light-response curve remains suspect, we feel that our overall conclusion, that shoaling decreases gradually as illumination decreases, is supported by our data.

The lack of a discrete light threshold for shoaling may be a general characteristic of fish which routinely engage in shoaling, as opposed to schooling behavior. Schooling fish continue to maintain precise distances and angular relationships between individuals as illumination decreases, but when illumination falls below the threshold, schooling abruptly ceases. Shoals are more chaotic in nature, with distances, angles and even direction of movement differing considerably between individuals. The less rigid behavior of shoalers, combined with the tendency of individual juvenile walleye pollock to continually leave and rejoin shoals, is likely to be responsible for the lack of a distinct light threshold for shoaling in this species. A gradual decrease in shoaling with lowered light has also been observed in Astyanax mexicanus (John 1964). It would be instructive to examine whether or not a light threshold is manifest in species like the walleye pollock, when the fish are motivated to engage in more rigid schooling behavior.

Although we observed that shoal cohesion changes linearly with the natural log of illumination, we also saw what appeared to be a discontinuity in shoal cohesion occurring at $4.0 \times 10^{-4} \mu \mathrm{E} \mathrm{s}^{-1} \mathrm{~m}^{-2}$ (Fig. 3b). Although we can ascribe no statistical significance to this discontinuity, its occurrence on both the ascending and descending limbs of the light response curve (Fig. 3a) suggests that some aspect of vision or behavior changes at this light level. One possibility is that this is the light level at which walleye pollock switch from photopic to scotopic vision. While highly speculative, this hypothesis could be tested by studying the retinomotor responses of juvenile walleye pollock to various illuminations.

Our laboratory data suggest that at light levels below $2.8 \times 10^{-6} \mu \mathrm{E} \mathrm{s}^{-1} \mathrm{~m}^{-2}$; those likely to be encountered in North Pacific surface waters on a clear moonless night, juvenile walleye pollock would be so dispersed as to no longer constitute a distinct shoal. However, with moonlight, shoaling could occur at greater depths, depending on lunar stage, cloud cover and water clarity. Brodeur \& Wilson (1996) reported that juvenile walleye pollock in the western Gulf of Alaska dispersed at a depth of $35 \mathrm{~m}$ during the night and actively fed upon larvaceans, copepods and euphausiids (Merati \& Brodeur 1996). Without data on ambient light levels at these depths on the nights concerned, it is impossible 
to characterize this dispersal as being the result of active or passive processes, but our laboratory data clearly suggest that the ability of juvenile walleye pollock to shoal will be greatly affected by astronomical and meteorological conditions, and that the ability of fish to shoal at this depth will probably vary from night to night.

Whereas the diurnal pattern of shoaling behavior in juvenile walleye pollock appears to represent a simple response to available light, the diel pattern of swimming speed was more complex. There was a tendency for swimming speeds to be lower in the dark than in the light, although the statistical significance of this effect varied between experiments. Many species of fish decrease their activity or swimming speed at night (Helfman 1993). For visually oriented species, decreased activity may lower energetic costs during periods when fish are not actively feeding (Neilson \& Perry 1990, Sogard \& Olla 1996). Decreased activity may also facilitate the maintenance of congregations when there is insufficient light for visually mediated shoaling (Emery 1973). In addition to this modest light/dark effect, there was also a strong diel pattern of swimming speed, characterized by peak speeds during the early morning, which decreased through the day and then decreased further to uniformly low levels during the night. This pattern may represent an endogenous rhythm, superimposed upon the light/dark effect. Alternatively, increased morning activity may simply be stimulated by the end of an extended period of darkness. Whatever its proximal causation, increased morning activity may facilitate shoal reformation, as individuals and small groups seek to locate one another and form a larger shoal. If shoaling represents the primary defense against predation, increased energy expenditure to quickly reform shoals in the morning would be advantageous. Pitcher \& Turner (1986) observed that European minnows forgo feeding until they have formed shoals at dawn, suggesting that mitigation of predation risk takes precedence over feeding during this vulnerable twilight

This superimposition of a diel pattern upon a generalized light/dark effect may explain the confusing results obtained in our threshold experiment, where swimming speed tended to decrease as the lights were dimmed, but did not increase again as the lights were turned back up. These trials commenced at 09:00 $\mathrm{h}$, when fish were engaged in their most rapid swimming of the day, as indicated by our periodicity experiment, but ended in the afternoon, when fish would typically have been swimming more slowly. This diel pattern, combined with the variability of our data, may have confounded our ability to clearly discriminate the effect of light intensity upon swimming speed in this particular experiment.
The importance of shoaling and/or schooling in predator avoidance has been clearly established and it has been widely observed that when there is adequate light for such behavior, the presence of predators typically results in shoals or schools becoming more compact (Maguran \& Pitcher 1987, Morgan 1988, Ryer \& Olla 1996). The 'many eyes' in a cohesive group are able to detect predators more efficiently than individuals (Maguran et al. 1985) and coordinated escape responses produce predator confusion (Neill \& Cullen 1974, Partridge \& Pitcher 1980, Landeau \& Terborgh 1986). However, prior studies of predation risk and group cohesiveness in juvenile walleye pollock have produced mixed results. Ryer \& Olla (1997) demonstrated that juvenile walleye pollock exposed to predatory sablefish shoaled more cohesively, but that the extent of this effect was influenced by whether or not the walleye pollock were foraging, as well as the spatial and temporal distribution of their food. Similarly, Sogard \& Olla (1998) reported that whether or not group cohesion increased in the face of predation risk depended upon juvenile walleye pollock size and hunger state. In the live predator trials of the present study, we saw only a weak trend for greater group cohesiveness. The small size of our infrared arena and the large number of fish used in this experiment, compared, that is, to our prior study utilizing the sablefish/walleye pollock predator/prey pairing (Ryer \& Olla 1997), may have influenced our results. The predator was often intermingled with the juvenile walleye pollock and, with fish moving in different directions to avoid the predator, this often disrupted shoaling. We also failed to see a strong effect of predation risk upon shoal cohesion in our model predator experiment. Sogard \& Olla (1998) found that, although juveniles will shoal more cohesively after presentation of a model predator, this response is weaker than that elicited by a living predator. Cumulatively, these studies indicate that juvenile walleye pollock do tend to shoal in the presence of predators; however, this is not an immutable relationship, as other environmental and motivational factors also help determine the structure and cohesiveness of fish shoals.

In the light, the effect of predation risk upon juvenile walleye pollock swimming speed differed between the simulated and live predator trials. In simulated predator trials, where the model predator made a brief but dramatic appearance, fish increased their swimming speed. However, in live predator trials, fish decreased swimming speed the same effect as that observed in a prior study where juvenile walleye pollock experienced persistent exposure to sablefish predation risk (Ryer \& Olla 1997). This difference between predator treatments could be attributable to any of a number of factors. It may simply represent an acclimation to predator 
presence in live, as opposed to the simulated, predator trials, or subtle differences in the perceived risk associated with the 2 treatments. Alternatively, there may be a fundamental difference in how fish respond to intense, but brief, interactions with predators, compared to persistent interaction. Fish scattered and then froze in response to model predator exposure. Afterwards, fish were unable to relocate the source of perceived threat, and may have increased swimming speed to 'leave the area' before another attack could occur. In contrast, in the live predator trial, fish were in continual contact with the predator and may have decreased speed to increase their vigilance, while also decreasing their conspicuousness (Lazarus 1979). Predators have evolved preferences that exploit vulnerabilities in their prey, as suggested by a study of the predatory cichlid Aequidens pulcher, which exhibited greater attraction for more active, as opposed to less active, groups of guppies Poecilia reticulata (Krause \& Godin 1995). Whatever the reason for the differences between our predation treatments, a more exhaustive investigation into how fish respond to differing types of perceived risk, expanding on the work of Helfman (1989), would be of great assistance in the synthesis of a predatorprey literature which has staged and/or simulated predation risk using a wide variety of techniques.

Since light plays a pivotal role in shoaling and schooling, it also determines how fish respond to predators. At ninght or at depth, wiih insufficient light for fish to see one another, shoals and schools tend to disperse (Smith et al. 1993, present study). Even in the presence of a predator, when the motivation to maintain groups should be high, juvenile walleye pollock were unable to do so. This is similar to behavior reported for blacknose dace, which shoal in response to predators in the light, but fail to do so in the dark, irrespective of predator presence or absence (Cerri 1983). However, this does not mean that in the darkness, prey behavior is unaffected by predator presence. Juvenile walleye pollock exposed to either model or living predators in the dark swam faster than fish which were not so exposed, the opposite of what was seen in the light. This was not because they were chased by the predator in the darkness, or exhibited frequent overt avoidance behavior. Rather, the mere presence of larger fish swimming about in the tank appeared to stimulate more rapid swimming by juvenile walleye pollock. Although not explicitly demonstrated by our data, this behavioral response to predators could also influence the spatial distribution of fish in the darkness. In our experiments, fish were unable to disperse beyond the confines of the arena, but in the ocean, with fish swimming faster and lacking the ability to see one another, the random movements of individuals should lead to more rapid and complete dispersal of shoals than would occur un- der lower predation regimes. Thus, our results suggest that predation risk may have very different influences upon the spatial distribution of fish under light versus dark conditions. In the light, predation may, depending upon environmental conditions and fish motivational state, cause greater contagion in fish spatial distribution, while in the darkness it likely results in greater spatial dispersion.

While it is unclear whether predator-accelerated dispersal of prey would influence prey vulnerability in the darkness, these prey may find themselves particularly vulnerable the following morning. During morning twilight, fish are silhouetted against downwelling light from the surface, rendering them particularly vulnerable to predatory attack from below (Munz \& McFarland 1973). Attacks by predatory fish are often concentrated at twilight (Major 1977, Parrish 1992) when predators have this visual advantage over their prey (Helfman 1993) and when prey are less likely to detect stalking predators (Pitcher \& Turner 1986). With the onset of morning twilight, widely dispersed individuals will presumably take longer to locate conspecifics and reform shoals and schools, resulting in prolonged vulnerability and greater probability of being eaten.

In summary, juvenile walleye pollock are not characterized by a distinct light threshold at which shoaling ceases; rather, fish gradually disperse as illumination decreases. Our data indicate that juvenile walleye pollock would be unlikely to maintain any degree of shoaling in the ocean at illuminations below $2.8 \times 10^{-6}$ $\mu \mathrm{E} \mathrm{s}^{-1} \mathrm{~m}^{-2}$, conditions that could be expected in surface waters on a starlit night. Illumination may also influence how juvenile walleye pollock respond to predators. Exposure to either model or live predators in the dark caused juvenile walleye pollock to swim faster. This may result in more rapid and complete dispersal of shoals during the night, making individuals more vulnerable to predation at dawn.

\section{LITERATURE CITED}

Appenzeller AR, Leggett WC (1992) Bias in hydroacoustic estimates of fish abundance due to acoustic shadowing: evidence from day-night surveys of vertically migrating fish. Can J Fish Aquat Scl 49:2179-2189

Atz JW (1953) Orientation in schooling fishes. Proc Conf Orient Anim-ONR XX:103-130

Bailey KM (1989) Interaction between the vertical distribution of juvenile walleye pollock Theragra chalcogramma in the eastern Bering Sea, and cannibalism. Mar Ecol Prog Ser 53:205-213

Bertram BCR (1978) Living in groups: predators and prey. In: Krebs JR, Davies NB (eds) Behavioural ecology, an evolutionary approach. Blackwell Scientific Publications, Oxford, p 64-96

Blaxter JHS (1964) Spectral sensitivity of the herring, Clupea harengus L. J Exp Biol 41:155-162 
Blaxter JHS (1969) Visual thresholds and spectral sensitivity of flatfish larvae. J Exp Biol 51:221-230

Blaxter JHS, Parrish BB (1965) The importance of light in shoaling, avoidance of nets and vertical migration by herring. J Cons Perm Int Explor Mer 30(1):40-57

Breder CM Jr (1951) Studies on the structure of the fish school. Bull Am Mus Nat Hist 98:1-28

Brodeur RD, Wilson MT (1996) Mesoscale acoustic patterns of juvenile walleye pollock (Theragra chalcogramma) in the western Gulf of Alaska. Can J Fish Aquat Sci 53: $1951-1963$

Cerri RD (1983) The effect of light intensity of predator and prey behaviour in cyprinid fish: factors that influence prey risk. Anim Behav 31:736-742

Clark PJ, Evans FC (1954) Distance to nearest neighbor as a measure of spatial relationships in populations. Ecology 35:445-453

Day RW, Quinn GP (1989) Comparisons of treatments after an analysis of variance in ecology. Ecol Monogr 59(4): $433-463$

Emery AR (1.973) Preliminary comparisons of day and night habits of freshwater fish in Ontario lakes. J Fish Res Bd Can 30:761-774

Glass CW, Wardle CS, Mojsiewicz WR (1986) A light intensity threshold for schooling in the Atlantic mackerel, Scomber scombrus. J Fish Biol 29(Suppl A):71-81

Helfman GS (1979) Twilight activities of yellow perch, Perca flavescens. J Fish Res Bd Can 36:173-179

Helfman GS (1989) Threat-sensitive predator avoidance in damselfish-trumpetfish interactions. Behav Ecol Sociobiol $24: 47-58$

Helfman GS (1993) Fish behaviour by day, night and twilight. In: Pitcher TJ (ed) Behaviour of teleost fishes, 2nd edn. Chapman and Hall, London, p 479-512

Hicks C (1982) Fundamental concepts in the design of experiments, 3rd edn. Holt Rinehart and Winston, New York

Higgs DM, Fuiman LA (1996) Light intensity and schooling behaviour in larval gulf menhaden. J Fish Biol 48:979-9.91

Hunter JR (1968) Effects of light on schooling and feeding of jack mackerel, Trachurus symmetricus. J Fish Res Bd Can 25(2):393-407

John KR (1964) Illumination, vision, and schooling of Astyanax mexicanus (Fillipi). J Fish Res Bd Can 21(6):1453-1473

Keenleyside MHA (1955) Some aspects of the schooling behaviour of fish. Behaviour 8:183-247

Krause J, Godin JG (1995) Predator preferences for attacking particular prey group sizes: consequences for predator hunting success and prey predation risk. Anim Behav 50: $465-473$

Landeau L, Terborgh J (1986) Oddity and the 'confusion effect' in predation. Anim Behav 34:1372-1380

Lazarus J (1979) The early warning function of flocking in birds: an experimental study with captive quelea. Anim Behav 27:855-865

Livingston PA (1993) Importance of predation by groundfish, marine mammals and birds on walleye pollock Theragra chalcogramma and Pacific herring Clupea pallasi in the eastern Bering Sea. Mar Ecol Prog Ser 102:205-215

Magurran AE, Oulton WJ, Pitcher TJ (1985) Vigilant behaviour and shoal size in minnows. Z Tierpsychol 67:167-178

Magurran AE, Pitcher TJ (1987) Provenance, shoal size and the sociobiology of predator-evasion behaviour in minnow shoals. Proc R Soc Lond B 229:439-465

Major PF (1977) Predator-prey interactions in schooling fishes during periods of twilight: a study of the silverside Pranesus insularum in Hawaii. Fish Bull 75(2):415-426

McFarland WN (1986) Light in the sea-correlations with

Editorial responsibility: Otto Kinne (Editor),

Oldendorf/Luhe, Germany behaviors of fishes and invertebrates. Am Zool 26:389-401

McFarland WN, Ogden JC, Lythgoe JN (1979) The influence of light on the twilught migrations of grunts. Environ Biol Fish 4(1):9-22

Merati N, Brodeur RD (1996) Feeding habits and daily ration of juvenile walleye pollock. Theragra chalcogramma, in the western Gulf of Alaska. NOAA Tech Rep NMFS 126:65-79

Morgan MJ (1988) The effect of hunger, shoal size and the presence of a predator on shoal cohesiveness in bluntnose minnows, Pimephales notatus Rafinesque. J Fish Biol 32:963-971

Munz FW, McFarland WN (1973) The significance of spectral position in the rhodopsins of tropical marine fishes. Vision Res 13:1829-1874

Neill SRSJ, Cullen JM (1974) Experiments on whether schooling by their prey affects the hunting behaviour of cephalopods and fish predators. J Zool 172:549-569

Neilson JD, Perry RI (1990) Diel vertical migrations of marine fishes: an obligate or facultative process? Adv Mar Biol 26: $115-168$

Parrish JK (1992) Levels of diumal predation on a school of flat-iron herring, Harengula thrissina. Environ Biol Fish 34:257-263

Partridge BL, Pitcher TJ (1980) The sensory basis of fish schools: relative roles of lateral line and vision. J Comp Physiol 135:315-325

Pitcher TJ (1980) Some ecological consequences of fish school volumes. Freshwat Biol 10:539-544

Pitcher TJ, Parrish JK (1993) Functions of shoaling behaviour in teleosts. In: Pitcher TJ (ed) Behaviour of teleost fishes, 2nd edn. Chapman and Hall, London, p 363-439

Pitcher TJ, Turner JR (1986) Danger at dawn: experimental support for the twilight hypothesis in shoaling minnows. J Fish Biol 29(Suppl A):59-70

Ryer CH, Olla BL (1995) Influences of food distribution on fish foraging behaviour. Anim Behav 49:411-418

Ryer CH, Olla BL (1996) Social behavior of juvenile chum salmon, Oncorhynchus keta, under risk of predation: the influence of food distribution. Environ Biol Fish 45:75-83

Ryer $\mathrm{CH}$, Olla BL (1997) Altered search speed and growth: social versus independent foraging in two pelagic juvenile fishes. Mar Ecol Prog Ser 153:273-281

Ryer C.H, Olla BL (1998) Shifting the balance between foraging and predator avoidance: the importance of food distribution for a schooling pelagic forager. Environ Biol Fish (in press)

Shaw $\mathrm{E}$ (1961) Minimal light intensity and the dispersal of schooling fish. Bull Inst Océanogr 1213:1-8

Smith GW, Glass CW, Johnstone ADF, Mojsiewicz WR (1993) Diurnal patterns in the spatial relationships between saithe, Pollachius virens, schooling in the wild. J Fish Biol 43(Suppl A):315-325

Sogard SM, Olla BL (1996) Diel patterns of behavior in juvenile walleye pollock, Theragra chalcogramma. Environ Biol Fishes 47:379-386

Sogard SM, Olla BL (1998) The influence of hunger and predator risk on group cohesion in a pelagic fish, walleye pollock Theragra chalcogramma. Environ Biol Fish (in press)

Sokal RR, Rohlf FJ (1969) Biometry. WH Freeman, San Francisco

Tang Q, Jin X, Li F, Chen J, Wang W, Chen Y, Zhao X, Dai F (1996) Summer distribution and abundince of age-O walleye pollock. Theragra chalcogramma, in the Aleutian Basin. NOAA Tech Rep NMFS 126:35-45

Turner GF, Pitcher TI (1986) Attack abatement: a model for group protection by combined avoidance and dilution. Am Nat 128(2):228-240

Submitted: October 21, 1997; Accepted: April 1, 1998

Proots received from author(s): June 2, 1998 